\title{
MAYO Machine learning integration of SPECT myocardial perfusion imaging CLINIC and clinical data in MACE
}

F⿻

Alan Mendez, M.D. ${ }^{1}$, Jose P. Salas, M.D. ${ }^{2}$, Yara I. Tejeda, M.D. ${ }^{2}$, Efrain Gaxiola, M.D. ${ }^{3}$

${ }^{1}$ Department of Neurology, Mayo Clinic, Rochester, MN, ${ }^{2}$ Department of Cardiology, Hospital Angeles del Carmen, Jalisco, Mexico, ${ }^{3}$ Department of Cardiology, Sanatorio Guadalajara, Jalisco, Mexico

Mayo Clinic, Rochester, MN

\section{Introduction}

Implementation of machine learning (ML) algorithms in cardiology, particularly in the field of nuclear cardiology, has revolutionized individualized diagnosis and prognostic estimations of myocardial ischemiarelated major adverse cardiovascular events (MACE).

The use of non-invasive, high-quality imaging via single-photon emission computed tomography (SPECT) together with clinical data, improves accuracy of diagnosis and prognosis of MACE compared to traditional methods.

\section{Objective}

Analyze the evidence for diagnostic and prognostic estimations of the combined use of SPECT myocardial perfusion imaging (MPI) and clinical data using ML.

\section{Methods}

A literature search of databases (e.g. PubMed and SpringerLink) was refined to identify reports of combined SPECT MPI and clinical data using ML focusing on diagnostic and prognostic values in MACE outcomes.

\section{Studies}

\begin{tabular}{|c|c|c|c|}
\hline $\begin{array}{l}\text { Author/ } \\
\text { year }\end{array}$ & $\begin{array}{c}\text { Clinical } \\
\text { variables }\end{array}$ & ML algorithm & Objective \\
\hline $\begin{array}{l}\text { Arsanjani et } \\
\text { al., } 2013\end{array}$ & 8 & $\begin{array}{l}\text { Boosting } \\
\text { ensemble }\end{array}$ & $\begin{array}{l}\text { Improve SPECT } \\
\text { MPI diagnostic } \\
\text { accuracy }\end{array}$ \\
\hline $\begin{array}{l}\text { Arsanjani et } \\
\text { al., } 2015\end{array}$ & 20 & $\begin{array}{l}\text { Boosting } \\
\text { ensemble }\end{array}$ & $\begin{array}{l}\text { Prediction of } \\
\text { revascularization }\end{array}$ \\
\hline $\begin{array}{l}\text { Betancur et } \\
\text { al., } 2018\end{array}$ & 28 & $\begin{array}{l}\text { Boosting } \\
\text { ensemble }\end{array}$ & $\begin{array}{l}\text { Prediction of 3- } \\
\text { year risk of } \\
\text { MACE }\end{array}$ \\
\hline
\end{tabular}

ML data integration

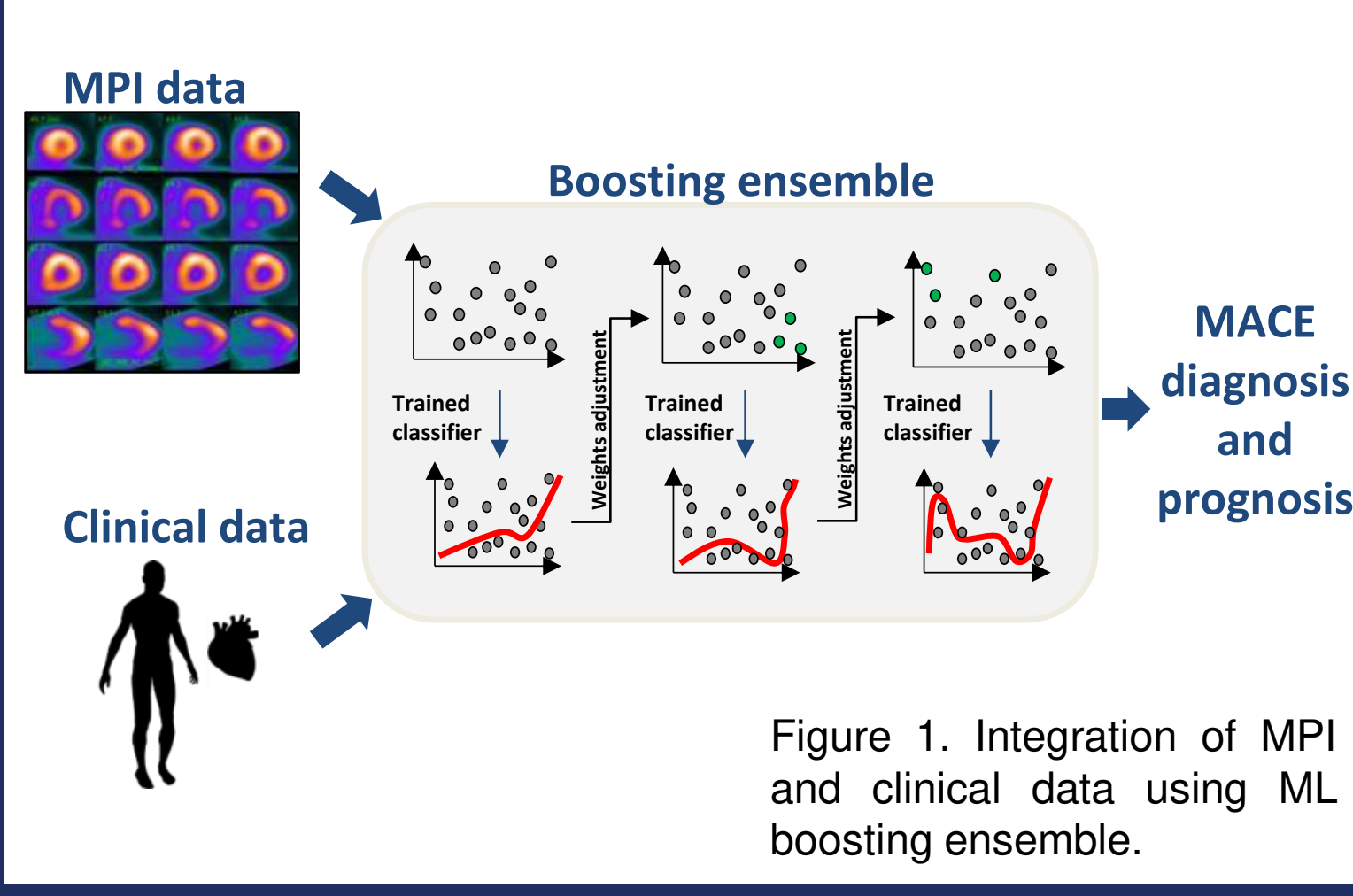

Results

ML diagnostic accuracy of coronary artery disease was superior to combined supine and prone total perfusion deficit (TPD) and to expert 2.

- ML predictive specificity for early revascularization was better than both expert readers and stress TPD.

- ML 3-year risk predictive accuracy of MACE was higher than MD diagnosis, automated stress TPD, and automated ischemic TPD.
ML Diagnostic Accuracy

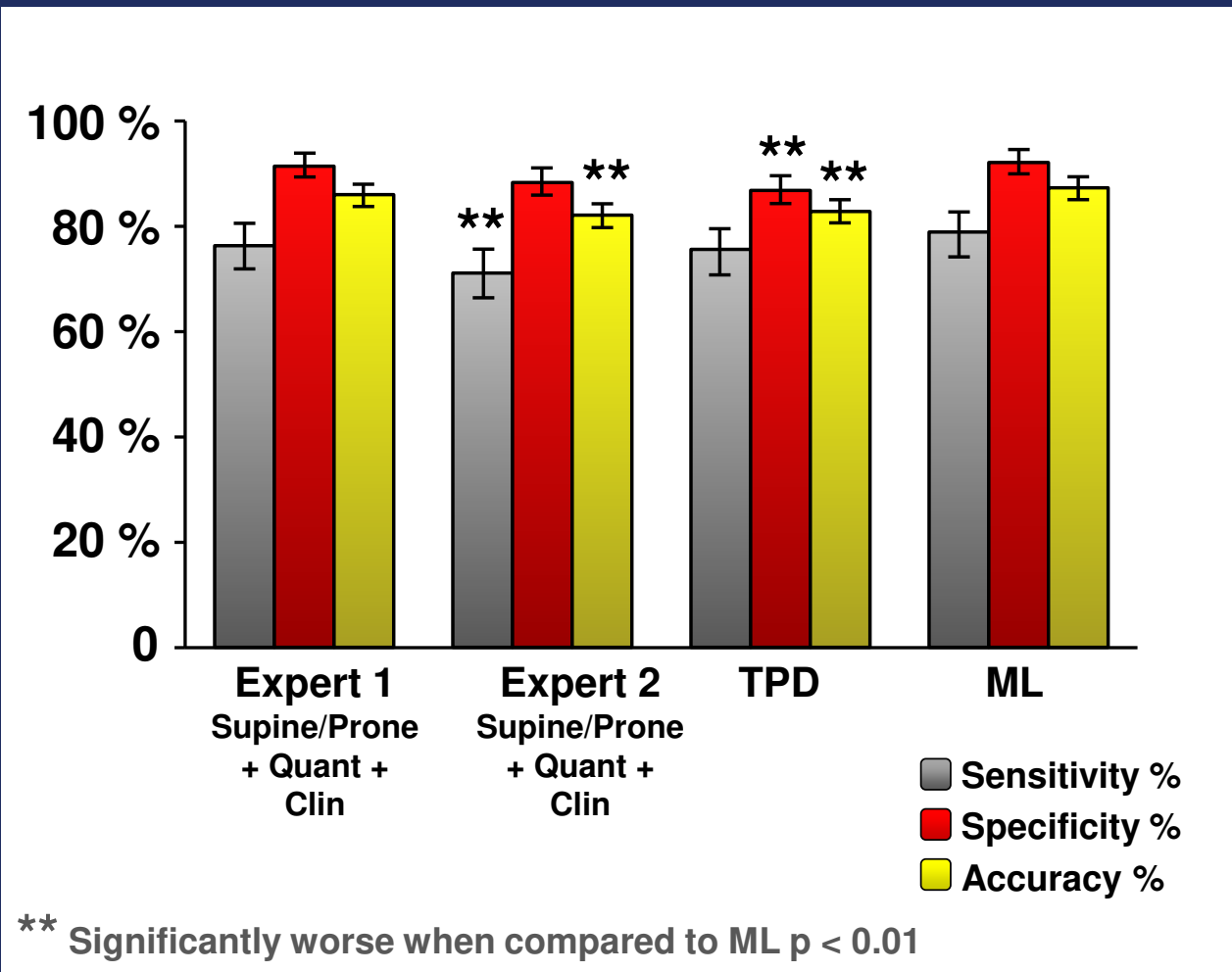

Prediction of Revascularization

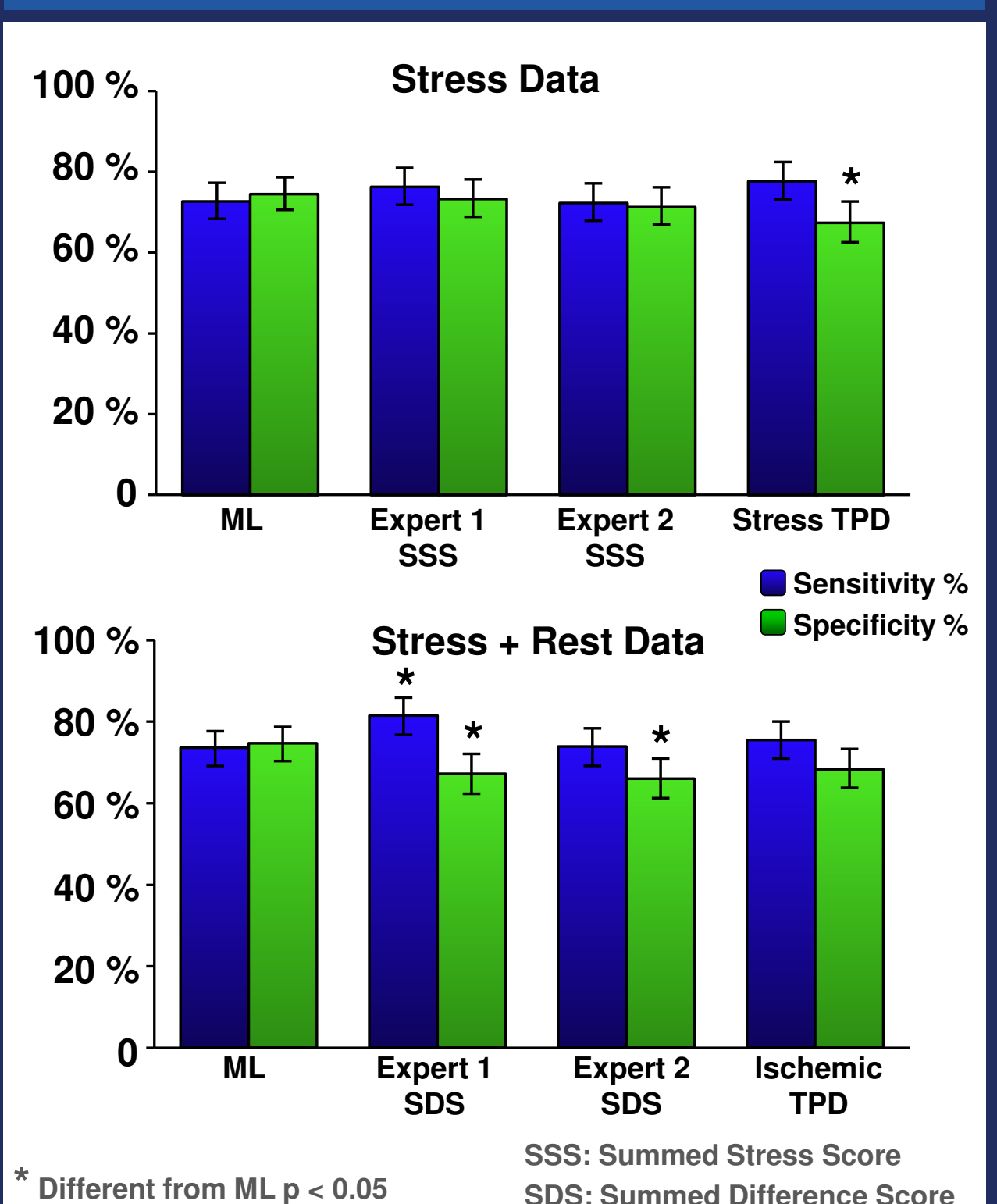

Prediction of 3-year MACE

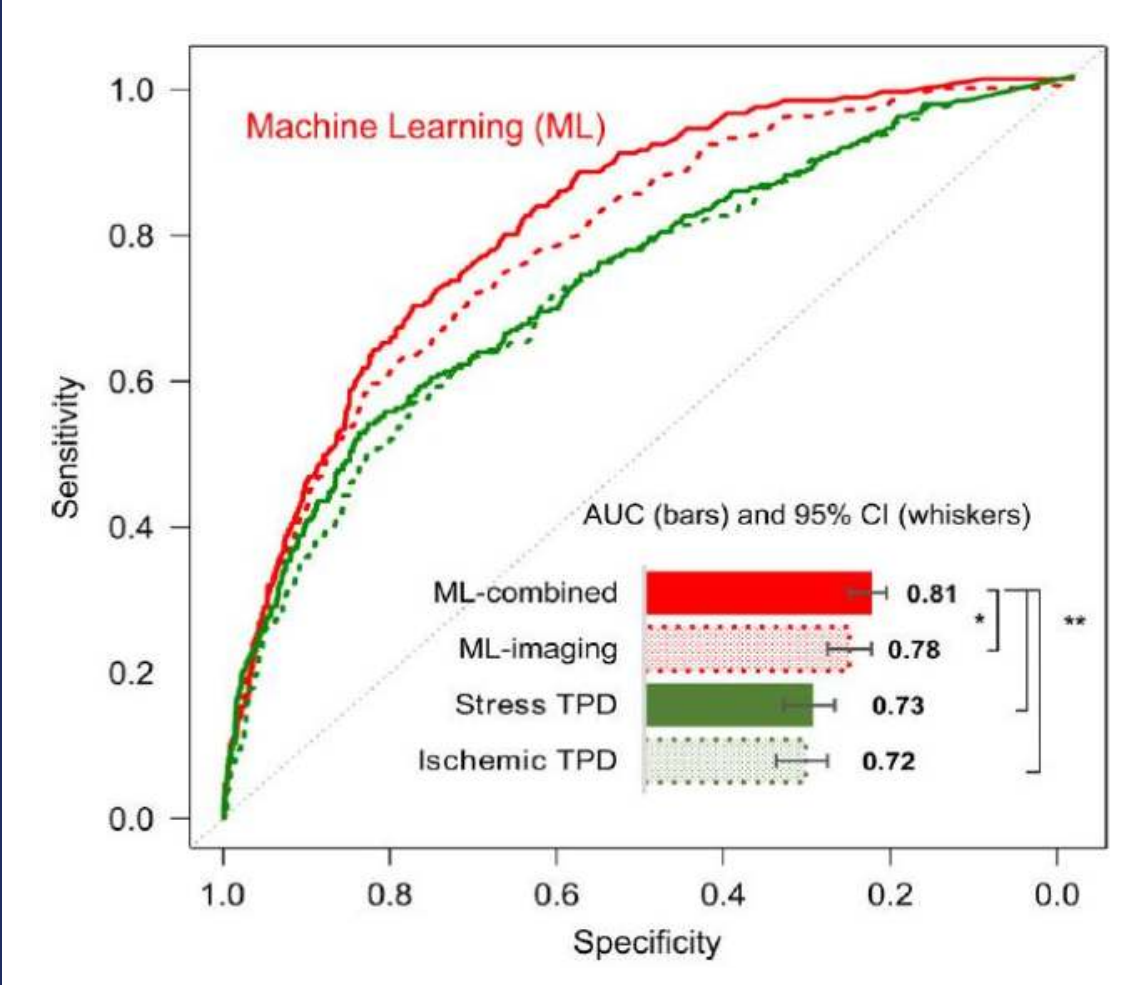

Conclusions

ML improved SPECT MPI diagnostic accuracy, and had a superior predictive accuracy for 3-year risk of MACE and for early revascularization after MPI.

The integration of MPI with clinical data via $M L$ is shown to be equally as effective, and in some instances a superior method to generate individualized diagnosis and prognoses of MACE in patients undergoing SPECT MPI.

References

Arsanjani R, et al. Improved accuracy of myocardia pertusion SPECT for delection of coronary artery disease by machine learning in a large population. J Nucl Cardiol. Prediction of revascularization after large population $J$ Nucl Cardio. 2015 Oct:22(5):877-84 Betancur J, et al. Prognostic Value of Combined Clinica and Myocardial Perfusion Imaging Data Using Machine Learning. JACC Cardiovasc Imaging. 2018 Jul;11(7):1000- 